\title{
Physicochemical Solubility of and Biological Sensitivity to Long-Chain Alcohols Determine the Cutoff Chain Length in Biological Activity ${ }^{\text {[ }}$
}

\author{
Atsushi Matsumoto and Yukifumi Uesono \\ Department of Biological Sciences, Graduate School of Science, The University of Tokyo, Tokyo, Japan \\ Received April 3, 2018; accepted September 26, 2018
}

\begin{abstract}
The cutoff phenomenon associated with the effectiveness of long-chain alcohols in the induction of anesthesia is also observed for various antimicrobial activities, although the mechanism has remained unknown for over eight decades. The minimum inhibitory concentrations at $25^{\circ} \mathrm{C}$ for budding yeast growth exponentially decreased with increasing chain length of $n$-alcohols $\left(\mathrm{C}_{2}-\mathrm{C}_{12}\right)$, whereas alcohols $\geq \mathrm{C}_{13}$ lost the inhibitory effect. Thus, growth inhibition by $n$-alcohols obeys the MeyerOverton correlation up to $\mathrm{C}_{12}$ and exhibits a cutoff phenomenon. The densities of $n$-alcohols are low, and the melting point and hydrophobicity increase with chain length. $\mathrm{C}_{13}$ and $\mathrm{C}_{14}$ inhibited yeast growth at $39.8^{\circ} \mathrm{C}$, above their melting points. Alcohols $\leq \mathrm{C}_{14}$ inhibited thermophilic bacterial growth at $50^{\circ} \mathrm{C}$, whereas $\mathrm{C}_{16}$ inhibited it at $67.5^{\circ} \mathrm{C}$, above their melting points. Thus, the high
\end{abstract}

melting points of long-chain alcohols contribute to the cutoff phenomenon. $\mathrm{C}_{14}$ did not effectively inhibit yeast growth in a static culture at $39.8^{\circ} \mathrm{C}$, in contrast to a shaking culture, in which the low density-dependent concentration gradient was eliminated. The duration of the transient growth inhibition of yeast by $\mathrm{C}_{12}$ was prolonged by sonication, which prevented hydrophobic aggregation. Therefore, a nonuniform distribution owing to low density and high hydrophobicity contributes to the cutoff. $\mathrm{C}_{14}$ inhibited the growth at $25^{\circ} \mathrm{C}$ of the pdr1,3,5 mutant, defective in multidrug efflux pumps, whereas $\mathrm{C}_{12}$ did not inhibit the growth of yeast overexpressing PDR5, indicating that the sensitivity to long-chain alcohols contributed to the cutoff. A balance between the physicochemical solubility of and the biological sensitivity to long-chain alcohols determines the cutoff chain length.

\section{Introduction}

The mechanism of anesthesia remains unclear because of the difficulty in explaining how various anesthetics cause similar anesthetic effects (Urban et al., 2006). The MeyerOverton correlation-the potency of various anesthetics correlates with the lipophilicity/hydrophobicity—-paved the way for the elucidation of this mechanism (Meyer, 1899; Overton, 1901). Initially, anesthetics were presumed to target membrane lipids as lipophilic sites according to the correlation. These are the so-called lipid theories (Antkowiak, 2001). The anesthetic "cutoff" is an unresolved phenomenon in which the anesthetic effects of $n$-alcohols increase with their chain lengths (lipophilicity/hydrophobicity), but long-chain alcohols $\left(\geq \mathrm{C}_{13}\right)$ abruptly lose their effects (Meyer and Hemmi, 1935; Pringle et al., 1981). This reproducible lack of correlation between the anesthetic potency and lipophilicity/hydrophobicity of long-chain alcohols contradicted the Meyer-Overton

This work was supported by the Sasakawa Scientific Research Grant [29-637] from The Japan Science Society to A.M., and the school fund of The University of Tokyo.

https://doi.org/10.1124/mol.118.112656.

S This article has supplemental material available at molpharm. aspetjournals.org. correlation, suggesting that the lipid theories are insufficient to explain the anesthetic mechanism.

Anesthetics and $n$-alcohols inhibited firefly luciferase activity in the absence of membrane lipids, suggesting a direct interaction between anesthetics and proteins (Ueda, 1965; Franks and Lieb, 1985). The inhibitory effects of $n$-alcohols increased with chain lengths, except for long-chain alcohols, indicating that the Meyer-Overton correlation and cutoff are also observed in luciferase inhibition. The protein theory was proposed to explain the Meyer-Overton correlation, the luciferase inhibition by anesthetics and $n$-alcohols, the cutoff effect, and other observations (Franks and Lieb, 1985, 1990). A simple hypothesis explaining the cutoff assumes that target proteins have hydrophobic anesthetic-binding pockets/clefts that fit various anesthetics but not long-chain compounds larger than the cutoff length. Accordingly, several membrane proteins with pockets are considered as target candidates (Urban et al., 2006). However, several reports raised questions about such pocket/clefts (Chiou et al., 1990; Eckenhoff et al., 1999; Cantor, 2001; Peoples and Ren, 2002; Mohr et al., 2005; Williams et al., 2007). $n$-Alcohols $\leq \mathrm{C}_{10}$ decrease the phasetransition temperature of the membrane model in response to chain length, whereas alcohols $\geq \mathrm{C}_{12}$ increase it. Thus, the Meyer-Overton correlation and cutoff may be explained by a

ABBREVIATIONS: ABC, ATP-binding cassette; DMF, $N, N$-dimethylformamide; GABA, $\gamma$-aminobutyric acid; HydC, hydrated concentration; logP, logarithm of octanol-water partition coefficient; MIC, minimum inhibitory concentration; MixC, mixed concentration; NMDA, N-methyl-D-asparate receptor; PDR, pleiotropic drug resistance; SD-U, synthetic complete dextrose medium minus uracil; TMA, trimethyl ammonium compounds; YPD, yeast extract peptone dextrose; YT, yeast extract tryptone. 
membrane alteration in the absence of protein, although the biological significance of the phase-transition temperature on anesthesia remains unknown (Kamaya et al., 1984). Recently, the cutoff phenomenon was observed in various biological systems, such as the sodium channel, gramicidin A channel formation, NMDA and GABA receptors, and cytokine production (Ingólfsson and Andersen, 2011; Carignan et al., 2013). These analyses explained the correlation between the biological phenomena and chain length at which the cutoff is observed (the cutoff chain length), but not the causation. At present, there remains no unified view to explain the cutoff.

$n$-Alcohols inhibit the growth of various microorganisms, and the inhibition potency increases with chain length, but long-chain alcohols lose this inhibitory effect (Gill and Ratledge, 1972; Teh, 1974; Kato and Shibasaki, 1980; Kubo et al., 1995, 2003; Mukherjee et al., 2013). Therefore, the MeyerOverton correlation and cutoff phenomenon are also observed in antimicrobial activity, indicating that these effects are not specific to anesthesia in animals and various biological systems. Moreover, the chain lengths for the antimicrobial cutoff $\left(\geq \mathrm{C}_{13}\right)$ are similar to those for anesthesia. Thus, the cutoff phenomenon may be caused either by the target common to organisms or the physicochemical properties of $n$-alcohols.

Trimethyl ammonium compounds (TMAs), one type of quaternary ammonium compound, are representative surfactants that have a cationic hydrophilic region and a hydrophobic alkyl chain and induce alcohol-like reactions in yeast, such as the inhibition of translation initiation and actin polarization. TMA-induced reactions also exhibit the Meyer-Overton correlation, but not the cutoff, even though the alkyl chain is $\mathrm{C}_{18}$ (Uesono et al., 2011). Dendritic tricarboxylato compounds with hydrophilic tricarboxyl groups and a long hydrophobic alkyl chain $\left(\leq \mathrm{C}_{22}\right)$ also do not exhibit the cutoff for antimicrobial activities (Williams et al., 2007). Because the water solubility of TMAs (TOXNET, https://toxnet.nlm.nih.gov) and tricarboxylato compounds is far higher than that of longchain alcohols, the physicochemical property of solubility may account for the cutoff of long-chain alcohols. Here, we focused on the causation between the physicochemical properties of $n$-alcohols and the cutoff in microorganisms.

\section{Materials and Methods}

Strains, Media, and Plasmids. Standard genetic manipulation of yeast and DNA manipulation were performed as described previously (Guthrie and Fink, 1991). The media used for the budding yeast Saccharomyces cerevisiae were YPD (yeast extract peptone dextrose: $1 \%$ yeast extract, $2 \%$ polypeptone, and $2 \%$ glucose) and SD-U (synthetic complete dextrose medium minus uracil: $2 \%$ glucose, $0.67 \%$ yeast nitrogen base, $0.5 \%$ casamino acids, $20 \mathrm{mg} / \mathrm{l}$ tryptophan, and $20 \mathrm{mg} / \mathrm{l}$ adenine sulfate). Sodium phosphate buffer ( $\mathrm{pH} \mathrm{6.0)}$ was added into these media at the final concentration of $10 \mathrm{mM}$. The thermophilic bacterium Geobacillus stearothermophilus (NBRC12550) was purchased from Biologic Resource Center, NITE (Chiba, Japan). The medium used for the bacteria was $2 \times \mathrm{YT}$ (1.6\% Bacto tryptone, $1 \%$ yeast extract, $0.5 \% \mathrm{NaCl}$ ) containing $3 \mathrm{mM} \mathrm{MgSO}_{4}$ (Msadek et al., 1998). For overexpression of PDR5 (pleiotropic drug resistance 5), the PDR5 fragment was cloned into the yeast multicopy vector YEp24 (YEp24-PDR5), a gift from Y. Tsujimoto (Tsujimoto et al., 2015). The $p d r 5$ knockout strain and the $p d r 1, p d r 3$, and $p d r 5$ triple-knockout strain were a gift from M. Mizunuma (Tutulan-Cunita et al., 2005). The yeast strains used in this study are listed in Table 1.

Chemicals. The $n$-alcohols, ethanol $\left(\mathrm{C}_{2}\right)$, 1-propanol $\left(\mathrm{C}_{3}\right)$, 1-butanol $\left(\mathrm{C}_{4}\right)$, 1-hexanol $\left(\mathrm{C}_{6}\right)$, 1-octanol $\left(\mathrm{C}_{8}\right)$, 1-decanol $\left(\mathrm{C}_{10}\right)$, 1-tridecanol $\left(\mathrm{C}_{13}\right)$, 1-tetradecanol $\left(\mathrm{C}_{14}\right)$, 1-hexadecanol $\left(\mathrm{C}_{16}\right)$, oleyl alcohol $\left(\mathrm{C}_{18: 1}\right)$, and Sudan III were purchased from Wako Pure Chemicals (Tokyo, Japan). 1-Dodecanol $\left(\mathrm{C}_{12}\right)$ and 1-octadecanol $\left(\mathrm{C}_{18}\right)$ were purchased from Tokyo Chemical Industry (Tokyo, Japan).

Determination of the Minimum Inhibitory Concentration. The minimum inhibitory concentration (MICs) of microorganisms were determined as described previously (Kubo et al., 1995). Microbial growths were performed in test tubes, microtubes, and 96-well microtiter plates (Corning, Corning, NY), and the growths $\left(\mathrm{OD}_{600}\right)$ were monitored by a UV spectrophotometer (Amersham Ultrospec 1100 Pro). Logarithmic cultures of the yeast strains grown in YPD (pH 6.0 ) and the yeast strains harboring the plasmids grown in SD-U $(\mathrm{pH}$ $6.0)$ at $25^{\circ} \mathrm{C}$ for 24 hours were inoculated into YPD (pH 6.0) $\left(\mathrm{OD}_{600}=\right.$ $0.05 ; 7.5 \times 10^{5}$ cells $\left./ \mathrm{ml}\right)$ and incubated at the indicated temperatures. Logarithmic cultures of thermophilic bacterium grown in $2 \times \mathrm{YT}$ containing $\mathrm{MgSO}_{4}$ at $50^{\circ} \mathrm{C}$ were inoculated into the same medium $\left(\mathrm{OD}_{600}=0.05 ; 2 \times 10^{7}\right.$ cells $\left./ \mathrm{ml}\right)$ and incubated at the indicated temperatures. The long-chain alcohols $\left(\geq \mathrm{C}_{6}\right)$ were first dissolved in $N, N$-dimethylformamide (DMF), and serial 2-fold dilutions were performed in DMF. The diluted solutions $(5 \mu \mathrm{l})$ were added to the sterile media (final $500 \mu \mathrm{l}$ ) containing the cells in test tubes and microtubes at the indicated concentrations of alcohols. The final concentration (1\%) of DMF did not affect the microbial growth. The short-chain alcohols $\left(\leq \mathrm{C}_{4}\right)$ were added directly to the media containing the cells, and serial 2 -fold dilutions were performed in the same media. These samples were incubated with or without shaking for the indicated times and at the indicated temperatures. For the 96-well microtiter plates, $100 \mu \mathrm{l}$ of the above media containing the dilution series of long-chain alcohols was used without dilution on the plate, and then incubated without shaking. The MIC of the test compound was the lowest concentration that completely inhibited microbial growth, as judged by visual observation or spectrophotometric determination.

Sonication. The medium containing the alcohol aggregates $(1 \mathrm{mM}$ $\mathrm{C}_{12}, 1 \% \mathrm{DMF}$ ) was sonicated in a microtube (pulse, 5 seconds; output level, 5), using an ultrasonic disruptor (UD201; TOMY, Tokyo, Japan) and then transferred to a test tube for monitoring of the growths $\left(\mathrm{OD}_{600}\right)$. To visualize the alcohol behavior in water by sonication, we used Sudan III dye that is a poorly soluble in water but soluble in $\mathrm{C}_{12}$. The $\mathrm{C}_{12}$ solution containing $1 \%$ Sudan III was mixed with water $\left(10 \mathrm{mM}\right.$ of $\left.\mathrm{C}_{12}\right)$ and sonicated in a microtube, and then transferred to a test tube.

Data Analysis. Statistical analyses of yeast growth were performed by one-way analysis of variance with the Tukey-Kramer multiple comparison test, using the $\mathrm{R}$ statistical software package (ver. 3.5.0; R Development Core Team 2018).

TABLE 1

Yeast strains used in this study

\begin{tabular}{|c|c|c|}
\hline Strain & Genotype & Sources \\
\hline BY4741 & MATa his $3 \Delta 1$ leu $2 \Delta 0$ ura $3 \Delta 0$ met $15 \Delta 0$ & EUROSCARF collection \\
\hline W303-1A & MATa ade2-1 his3-11,15 leu2-3,112 trp1-1 ura3-1can1-100 ssd1-d2 & Our strain collection \\
\hline YYU701 & W303-1B MAT $\alpha$ pdr5 $4:: L E U 2$ & Tutulan-Cunita et al. (2005) \\
\hline YYU702 & 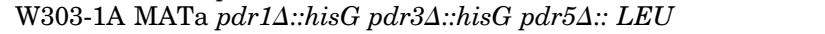 & Tutulan-Cunita et al. (2005) \\
\hline
\end{tabular}




\section{Results}

A Comparison between the Aqueous Solubility of Alcohols on the Basis of Chain Length and Minimum Inhibitory Concentrations against Yeast. At $25^{\circ} \mathrm{C}$ for 24 hours, the MICs of budding yeast (S. cerevisiae) growth exponentially decreased with increasing chain lengths of $\mathrm{C}_{2}$ $\mathrm{C}_{12}$, whereas longer alcohols $\left(\geq \mathrm{C}_{13}\right.$ ) lost their inhibitory effect, even though these were added in excess $(\geq 10 \mathrm{mM}$ ) (Fig. 1, red circles). Thus, the inhibition of yeast growth by $n$-alcohols obeys the Meyer-Overton correlation up to $\mathrm{C}_{12}$ and exhibits the cutoff phenomenon, as reported previously (Gill and Ratledge, 1972; Teh, 1974; Kato and Shibasaki, 1980; Kubo et al., 1995, 2003). Comparing the MICs with the aqueous solubility $\left(\mathrm{S}_{\mathrm{W}}\right)$ of $n$-alcohols (Bell, 1973), the MICs of the alcohols $\leq \mathrm{C}_{10}$ were lower than the solubility, but the MIC of $\mathrm{C}_{12}$ was higher than the solubility (Fig. 1). Similar trends were observed for the inhibition of luciferase, the NMDA receptor, and immunomodulatory activity (Franks and Lieb, 1985; Peoples and Ren, 2002; Carignan et al., 2013), suggesting that the correlation with $S_{\mathrm{W}}$ is not specific for yeast growth inhibition. This result suggests that the aqueous solubility of shorter-chain alcohols $\left(\leq \mathrm{C}_{10}\right)$ reaches the MIC, but those of the longer-chain alcohols $\left(\geq \mathrm{C}_{12}\right)$ do not. According to this hypothesis, the $\mathrm{C}_{12}$ alcohol is considered to be the cutoff compounds; however, $\mathrm{C}_{12}$ inhibited growth. To explain this finding, we determine whether the aqueous solubility of $n$ alcohols affects the biological activity.

Physicochemical Properties to Determine the Solubility of $n$-Alcohols. The solubility of long-chain $n$-alcohols in water is very low because of their physicochemical properties. First, all densities of the $n$-alcohols are lower than that of water (Supplemental Table 1). Water molecules interact with each other through hydrogen bonds, forming a hydrogen bond network. The aqueous solubility of an $n$-alcohol is determined by the hydrogen bonds between the hydroxyl group of the $n$ alcohol and water molecules. In addition to hydrogen bonds, short-chain alcohols $\left(\leq \mathrm{C}_{3}\right)$ are trapped in the hydrogen bond

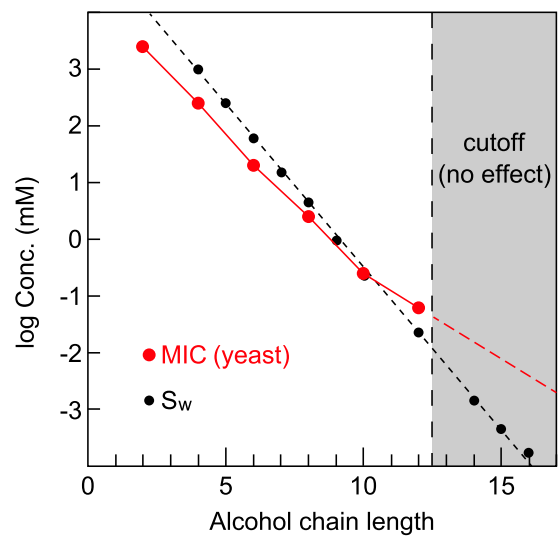

Fig. 1. A comparison between the aqueous solubilities of $n$-alcohols and the minimum inhibitory concentrations of yeast. The MICs of $n$-alcohols $\mathrm{C}_{2}-\mathrm{C}_{18}$ were measured in yeast (BY4741) after 24 hours in YPD with shaking at $25^{\circ} \mathrm{C}$. The alcohols $\left(\mathrm{C}_{13}-\mathrm{C}_{18}\right)$ did not inhibit yeast growth, even at $10 \mathrm{mM}$. The area containing the cutoff alcohols $\left(\mathrm{C}_{13}-\mathrm{C}_{18}\right)$ is indicated with the gray zone. The $\log$ MICs $\left(\mathrm{C}_{2}-\mathrm{C}_{12}\right)$ (red circles) and the log aqueous solubility ( $\mathrm{S}_{\mathrm{W}}$ ) of $n$-alcohols $\mathrm{C}_{2}-\mathrm{C}_{16}$ (Bell, 1973) (black circles) are plotted against the number of carbons in the alkyl chain. The dotted red line indicates the extrapolated the MICs of yeast. The MICs of three independent experiments were identical. network and are efficiently miscible in water (Fig. $2 \mathrm{~A}, \mathrm{C}_{2}$ ), whereas long-chain alcohols $\left(\geq \mathrm{C}_{4}\right)$ are not trapped because they would destroy the network. Consequently, long-chain alcohols $\left(\geq \mathrm{C}_{4}\right)$ separate from water and float owing to their specific densities (Fig. 2A, lower panel $\mathrm{C}_{4}-\mathrm{C}_{12}$ ). Second, in the upper layer, van der Waals forces among the alkyl chains increase with chain length, resulting in an increase in the melting point (Supplemental Table 1). For example, $\mathrm{C}_{14}$ is solid owing to the formation of a crystal structure at $25^{\circ} \mathrm{C}$, which is lower than its $\mathrm{mp}\left(37.7^{\circ} \mathrm{C}\right)$ (Fig. $\left.2 \mathrm{~A}\right)$. Third, the hydrophobicity/lipophilicity of $n$-alcohols, expressed as the octanol-water partition coefficient $(\log \mathrm{P})$, increases with an increase in the hydrophobic alkyl chain length and a decrease in the relative abundance of hydrogen bonds (Supplemental Table 1). Therefore, long-chain alcohols aggregated and separated rapidly from the medium after mixing owing to the hydrophobic interactions defined by the chain lengths (Fig. 2A, 0.5 minutes). Because the liquid alcohols $\left(\mathrm{C}_{4}-\mathrm{C}_{12}\right)$ have similar densities (Supplemental Table 1), the aggregation/separation rates depend on the hydrophobicity, rather than the density and melting point.

In the lower layer (Fig. 2B), long-chain alcohol molecules hydrogen-bond with water molecules and exist in a hydrated state (hydrated concentration: HydC). HydC exponentially decreases with chain length because of the decrease in the relative contribution of hydrogen bonds, regardless of the solid/liquid state (Fig. 2B, black circles). In addition,

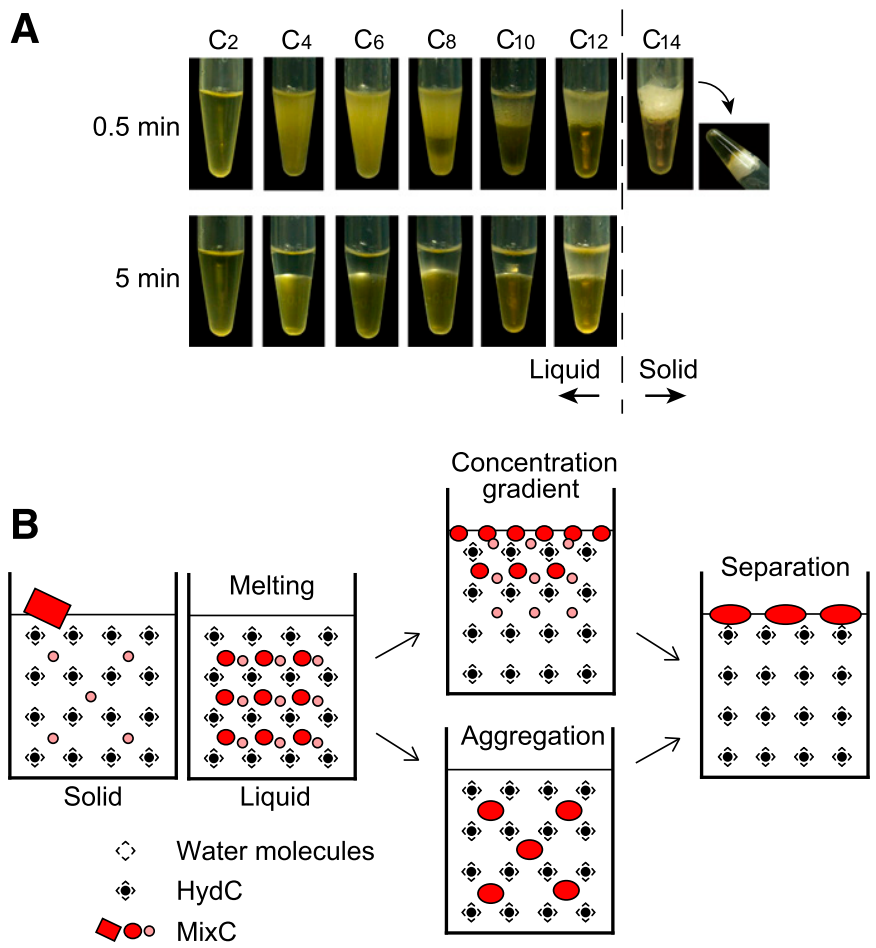

Fig. 2. States of $n$-alcohols in aqueous solutions. (A) $n$-Alcohols $\mathrm{C}_{2}-\mathrm{C}_{14}$ $(500 \mu \mathrm{l})$ were mixed with equal amounts of YPD using a microtube mixer at top speed for 5 seconds and were then observed after 0.5 and 5 minutes at $25^{\circ} \mathrm{C}$. $\mathrm{C}_{2}$ to $\mathrm{C}_{12}$ alcohols were liquid, but $\mathrm{C}_{14}$ was solid at $25^{\circ} \mathrm{C}$. (B) States of the long-chain alcohols (solid/liquid) in the aqueous solution after mixing. The long-chain alcohol molecules hydrogen-bond with water molecules and exist in the hydrated state. The long-chain alcohol droplets/particles $\left(\geq \mathrm{C}_{4}\right)$ simply mix with water without stable hydrogen bonds and exist in the mixed state. The MixC is unstable because of its low density (concentration gradient) and high hydrophobicity (aggregation). 
long-chain alcohol droplets/particles $\geq \mathrm{C}_{4}$ simply mix with water without stable hydrogen bonds and exist in a mixed state (mixed concentration: MixC). MixC is unstable because the droplets/particles separate from water and aggregate owing to high hydrophobicity and float on water owing to the low density (Fig. 2B, red/pink figures). For example, in the lower layer, the solubility of the supersaturated $\mathrm{C}_{16}$ solution gradually decreased over 20 days, and reached an equilibrium concentration (Krause and Lange, 1965). The gradual decrease resulted from a decrease in the unstable $\mathrm{MixC}$, and the equilibrium concentration corresponded to HydC (Fig. 2B).

The equilibrated solubility of organic nonelectrolytes in water is estimated by the equations for liquid (eq. 1) and the solid solutes (eq. 2) (Jain and Yalkowsky, 2001).

$$
\begin{gathered}
\log \mathrm{S}^{\text {liquid }}=0.5-\log \mathrm{P}_{\mathrm{OW}} \\
\log \mathrm{S}^{\text {solid }}=0.5-0.01(\mathrm{mp}-25)-\log \mathrm{P}_{\mathrm{OW}}
\end{gathered}
$$

where $\mathrm{S}^{\text {liquid }}$ is the solubility of the liquid in water, $\mathrm{S}^{\text {solid }}$ is the solubility of the solid in water, $\log \mathrm{P}_{\mathrm{OW}}$ is the octanol-water partition coefficient (Supplemental Table 1), mp is melting point, and 25 is room temperature. These are applicable to the equilibrated solubility (HydC) of long-chain alcohols in water. According to the equations, the HydC of the solid alcohol is estimated by eq. 2 at room temperature. When the solid alcohol is melted at high temperature, its HydC is estimated by eq. 1 . Thus, the HydC of the melted alcohol is higher than that of the solid alcohol. Indeed, the solubility of solid alcohols increases at high temperatures compared with the solubility of liquid alcohols (Krause and Lange, 1965). Consequently, the hydrophobicity (partition coefficient) and melting point are important factors for estimating the HydC, although an effective method to estimate the unstable MixC remains unknown.

Important for organisms living in an aqueous solution is the total solubility in the lower, which consists of both the stable HydC and unstable MixC. These properties of $n$-alcohols are observed even at the low concentrations used for assessing anesthetic and antimicrobial activities. Importantly, the total solubility of long-chain alcohols is largely affected by physicochemical conditions. We examined the causation between these physicochemical properties of $n$-alcohols and the cutoff phenomenon.

Low Solubility owing to the High Melting Point of Long-Chain Alcohols Contributes to the Cutoff. Alcohols $\leq \mathrm{C}_{12}\left(\mathrm{mp}: \leq 24^{\circ} \mathrm{C}\right)$ with anesthetic and antimicrobial activities are liquid at $25^{\circ} \mathrm{C}$, whereas alcohols $\geq \mathrm{C}_{13}\left(\mathrm{mp}: \geq 32.5^{\circ} \mathrm{C}\right)$ without those activities are solid (Supplemental Table 1), suggesting that the solid phase may influence the cutoff. Because the solubility of solid alcohols is increased by melting (Krause and Lange, 1965) (Fig. 2B, Melting), we measured the MICs of $n$-alcohols on yeast growth at a high temperature. Alcohols $\mathrm{C}_{13}\left(\mathrm{mp}: 32.5^{\circ} \mathrm{C}\right)$ and $\mathrm{C}_{14}$ (mp: $37.7^{\circ} \mathrm{C}$ ) inhibited yeast growth at $39.8^{\circ} \mathrm{C}$ when they were melted, but other alcohols $\left(\geq \mathrm{C}_{16}, \mathrm{mp}: \geq 49.3^{\circ} \mathrm{C}\right) \operatorname{did} \operatorname{not}($ Fig. $3 \mathrm{~A})$, indicating that the melting of long-chain alcohols avoids the cutoff. However, the MIC of $\mathrm{C}_{14}$ was higher than that predicted by the Meyer-Overton correlation. Because $\mathrm{C}_{14}$ may be partially melted and the alcohols $\geq \mathrm{C}_{16}$ are not melted at $39.8^{\circ} \mathrm{C}$, limiting temperature for yeast growth, a higher temperature is required to precisely evaluate these MICs. Therefore, we used Geobacillus stearothermophilus, a Gram positive bacterium that can grow at $\sim 70^{\circ} \mathrm{C}$ (Fig. 3B). At $50^{\circ} \mathrm{C}$, the MICs exponentially decreased with

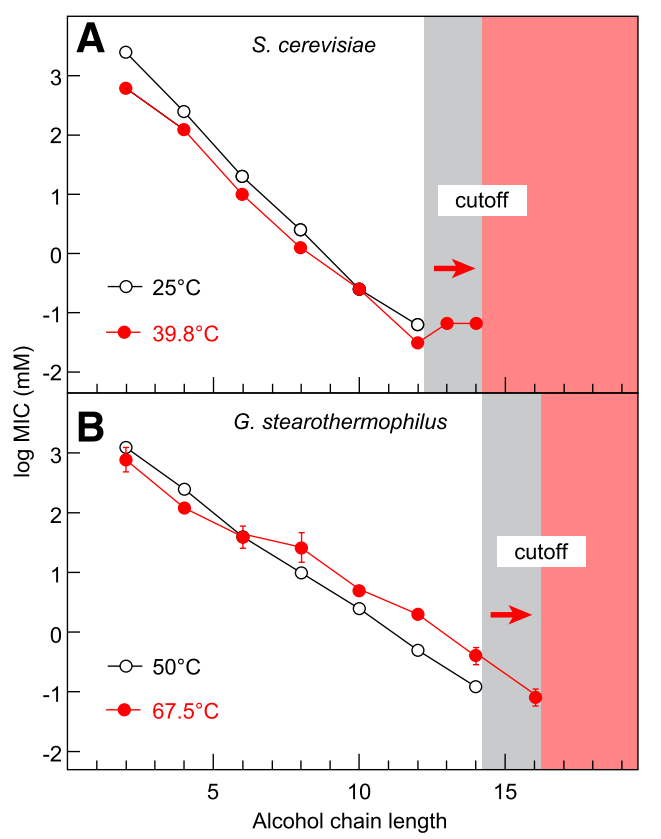

Fig. 3. Effects of temperature on the cutoff chain length of $n$-alcohols. The $\log$ MICs of $n$-alcohols $\left(\mathrm{C}_{2}-\mathrm{C}_{18}\right)$ for each microorganism are plotted against the number of carbons in the alkyl chain, except for the cutoff alcohols. (A) The MICs of the yeast strain (BY4741) after 24 hours in YPD with shaking at the indicated temperatures. (B) The MICs of the thermophilic bacterium G. stearothermophilus after 24 hours in $2 \times \mathrm{YT}$ containing $\mathrm{MgSO}_{4}$ with shaking at the indicated temperatures. The areas containing the cutoff alcohols with no growth inhibitory effect are indicated by the gray zones at low temperatures $\left(25^{\circ} \mathrm{C}\right.$ and $\left.50^{\circ} \mathrm{C}\right)$ and the red zone at high temperatures $\left(39.8^{\circ} \mathrm{C}\right.$ and $\left.67.5^{\circ} \mathrm{C}\right)$. Data are the means \pm S.D. of triplicate experiments.

chain length $\left(\mathrm{C}_{2}-\mathrm{C}_{14}\right)$, whereas alcohols $\geq \mathrm{C}_{16}$ lost their inhibitory effect. Thus, growth inhibition also obeys the MeyerOverton correlation and exhibits the cutoff phenomenon at $50^{\circ} \mathrm{C}$. At $67.5^{\circ} \mathrm{C}, \mathrm{C}_{16}$ also inhibited growth according to the correlation. These results indicate that the cutoff chain length increases with an increase in temperature regardless of the species. Destabilizing the solid-state structures of the long-chain alcohols with high temperatures increases the number of free molecules, thereby increasing the total solubility and allowing the MIC to be reached. Consequently, the low solubility resulting from the high melting points of long-chain alcohols contributes to the cutoff.

Concentration Gradient owing to the Low Density of Long-Chain Alcohols Contributes to the Cutoff. Because long-chain alcohols $\left(\geq \mathrm{C}_{4}\right)$ were concentrated in the upper layer of the medium owing to their low specific densities, the concentrations would be lower at the bottom in the static culture (Fig. 2B, concentration gradient). In the shaking culture, the concentration gradient formed by the low density would be eliminated. To test the effect of the gradient on growth, we used budding yeast that grows both at the bottom of the static culture and in the entire area of the shaking culture. As shown in Fig. 4A, yeast cells grew at the bottom of the static culture containing $\mathrm{C}_{14}(4 \times \mathrm{MIC})$ at $39.8^{\circ} \mathrm{C}$ when it was melted, but not in the shaking culture. This observation suggests that the concentration of $\mathrm{C}_{14}$ was lower in the bottom of the static culture than the shaking culture. No growth was observed in either of the cultures containing $\mathrm{C}_{2}$ $(1 \times \mathrm{MIC})$ at $25^{\circ} \mathrm{C}$ (Fig. $\left.4 \mathrm{~A}\right)$. Thus, $\mathrm{C}_{14}$ would form a gradient of the unstable MixC lower at the bottom, whereas the watermiscible $\mathrm{C}_{2}$ would not form a MixC gradient. Although $\mathrm{C}_{10}$ 

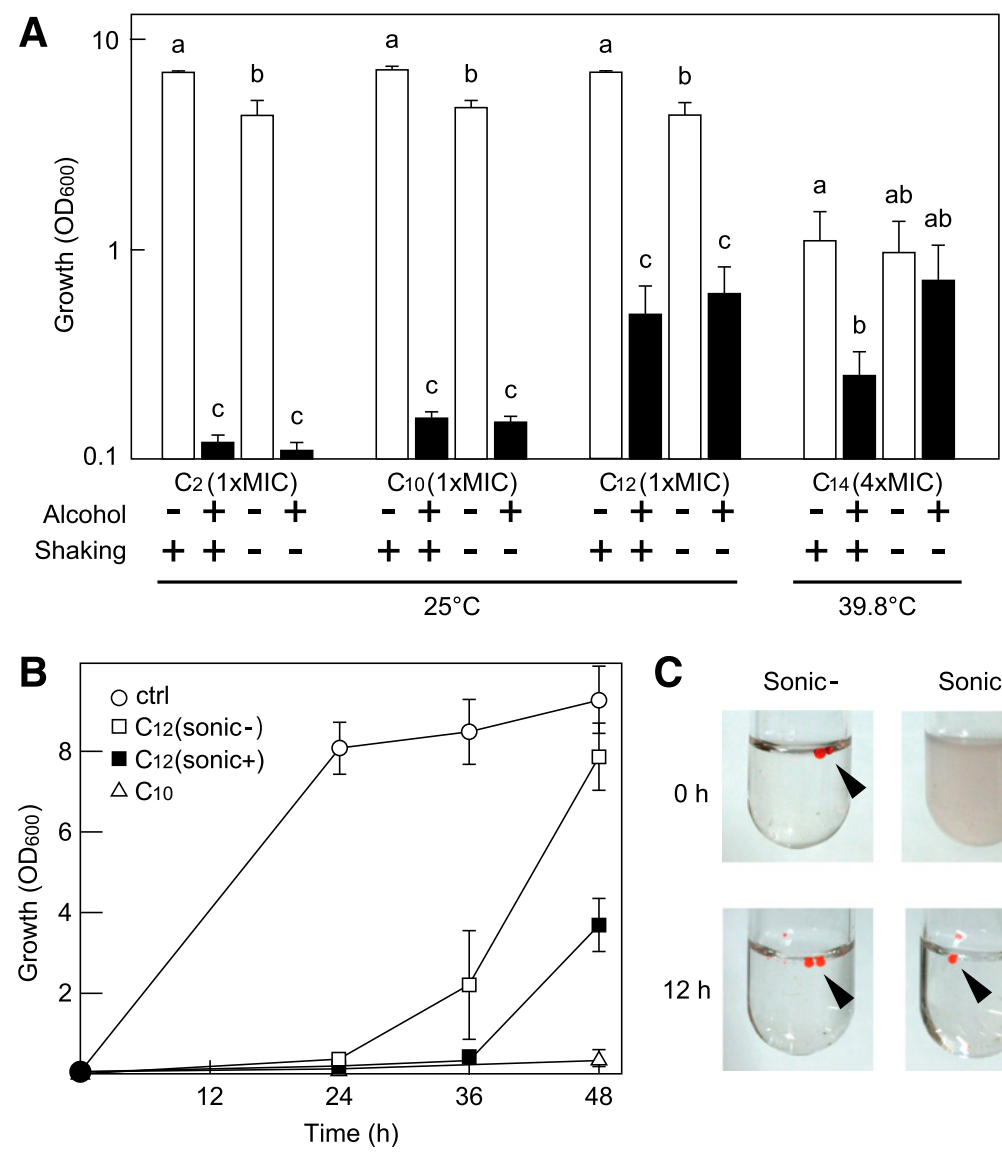

C Sonic-

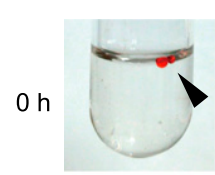

$12 \mathrm{~h}$

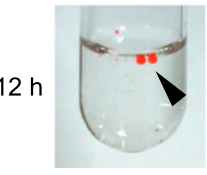

Sonic+
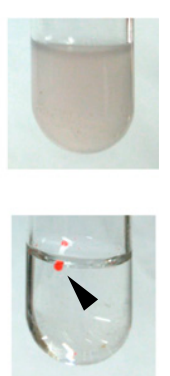

Fig. 4. Effects of culture methods on the growth inhibitory activity of long-chain alcohols. (A) The BY4741 cells were inoculated $\left(\mathrm{OD}_{600}=0.05\right)$ into $500 \mu \mathrm{l}$ of YPD containing $\mathrm{C}_{2}$ $(2.5 \mathrm{M}: 1 \times \mathrm{MIC}), \mathrm{C}_{10}(250 \mu \mathrm{M}$ in $1 \% \mathrm{DMF}$ : $1 \times \mathrm{xMIC}), \mathrm{C}_{12}$ $(63 \mu \mathrm{M}$ in $1 \%$ DMF: $1 \times \mathrm{MIC}), \mathrm{C}_{14}(250 \mu \mathrm{M}$ in $1 \%$ DMF: $4 \times$ MIC) (black bars), YPD without alcohols (for C2), and YPD containing $1 \% \mathrm{DMF}$ (for $\mathrm{C}_{10}, \mathrm{C}_{12}$, and $\mathrm{C}_{14}$ ) (white bars). Growth $\left(\mathrm{OD}_{600}\right)$ was monitored after 24 hours at the indicated temperatures in the shaking/static cultures of the microtubes. Data are the means \pm S.D. $(n \geq 3)$. Different letters denote significant differences using analysis of variance and Tukey-Kramer test at $P<0.05$. (B) The $\mathrm{OD}_{600} \mathrm{~s}$ of BY4741 was monitored at the indicated times in the shaking YPD cultures (500 $\mu \mathrm{l}$ in test tubes) containing $1 \% \mathrm{DMF}$ (circles), $\mathrm{C}_{10}(250 \mu \mathrm{M}$ in $1 \% \mathrm{DMF}: 1 \times \mathrm{MIC})$ (triangles), $\mathrm{C}_{12}(1000 \mu \mathrm{M}$ in $1 \% \mathrm{DMF}$ : $16 \times \mathrm{MIC})$ without sonication (squares), and $\mathrm{C}_{12}(16 \times \mathrm{MIC})$ with sonication (black squares). Data are the means \pm S.D. $(n \geq 3)$. (C) The $\mathrm{C}_{12}$ solutions containing $1 \%$ Sudan III were mixed with water (final $10 \mathrm{mM}$ ) and incubated for 12 hours with shaking. The nonsonicated (left) and sonicated solution (right) were indicated. The arrows indicate the aggregates of $\mathrm{C}_{12}$. should also form a gradient, no growth difference was observed in either culture containing $\mathrm{C}_{10}(1 \times \mathrm{MIC})$, suggesting that the $\mathrm{HydC}$ alone of $\mathrm{C}_{10}$ reaches the MIC at the bottom of the static culture, but that of $\mathrm{C}_{14}$ does not. Thus, the increase in the MixC of $\mathrm{C}_{14}$ by shaking increases the total solubility with the HydC, thereby reaching the MIC. Consequently, the concentration gradient owing to the low density of long-chain alcohols is involved in the cutoff.

Compared with $\mathrm{C}_{2}$ and $\mathrm{C}_{10}, \mathrm{C}_{12}(1 \times \mathrm{MIC})$ did not completely inhibit growth in a microtube, suggesting that the $\mathrm{HydC}$ of $\mathrm{C}_{12}$ also does not reach the MIC (Fig. 4A). However, no apparent difference in growth inhibition was observed in either culture, which differs from the case of $\mathrm{C}_{14}$, possibly because growth at $25^{\circ} \mathrm{C}$ is faster than at $39.8^{\circ} \mathrm{C}$, a severe growth condition. Therefore, the gradient elimination alone of $\mathrm{C}_{12}$ does not efficiently inhibit fast growth at $25^{\circ} \mathrm{C}$. Presumably, the efficient inhibition of fast growth by $\mathrm{C}_{12}$ requires a mechanism other than gradient elimination, as described below.

Nonuniform Distribution owing to the High Hydrophobicity of Long-Chain Alcohols Contributes to the Cutoff. Long-chain alcohols aggregate through hydrophobic interactions even in a shaking culture (Fig. 2B, Aggregation), thereby gradually decreasing the local MixC, which allows microbial growth. Indeed, $\mathrm{C}_{12}$ inhibited yeast growth for 24 hours in the shaking culture at $25^{\circ} \mathrm{C}$ but did not inhibit growth after 48 hours $(16 \times \mathrm{MIC})$, whereas $\mathrm{C}_{10}(1 \times \mathrm{MIC})$ inhibited growth after 72 hours, indicating that growth inhibition by $\mathrm{C}_{12}$ is transient (Fig. $4 \mathrm{~B}$ ). Therefore, $\mathrm{C}_{12}$ is also the cutoff compound if it is judged by long-term treatments, as expected in Fig. 1. This observation is consistent with previous reports (Kubo et al., 2003; Fujita et al., 2017). Presumably, the HydC alone of $\mathrm{C}_{10}$ would reach the $\mathrm{MIC}$, but that of $\mathrm{C}_{12}$ would not, although the total solubility $(\mathrm{HydC}+\mathrm{MixC})$ reaches the MIC. The decrease in the MixC by aggregation gradually reduces the total solubility even in the shaking culture, thereby causing transient growth inhibition. Therefore, if the hydrophobic aggregation of $\mathrm{C}_{12}$ is prevented and the MixC does not decrease, the growth remains inhibited. To confirm this, we sonicated the medium containing $\mathrm{C}_{12}$ to prevent aggregation. $\mathrm{C}_{12}$ in the aqueous solution was visualized with Sudan III, except for very small droplets. The sonicated $\mathrm{C}_{12}$ dispersed but gradually aggregated after 12 hours in a shaking aqueous solution, whereas it did not disperse without sonication (Fig. 4C). Yeast cells were inoculated into the sonicated medium and cultured in it with shaking. The duration of growth inhibition was prolonged in the sonicated medium compared with the nonsonicated medium (Fig. 4B). This increase in the duration of inhibition occurs because the prevention of aggregation delays the decrease in MixC. Therefore, the duration of the total solubility $(\mathrm{HydC}+\mathrm{MixC})$ reaching the MIC is extended, resulting in a prolonged duration of growth inhibition, regardless of the cellular states. Therefore, nonuniform distribution owing to the high hydrophobicity of long-chain alcohols contributes to the cutoff.

Biological Sensitivity to $\boldsymbol{n}$-Alcohols Contributes to the Cutoff. A variety of chain lengths for $n$-alcohols inhibit the growth of various microorganisms under similar physicochemical conditions, although the reason remains unknown (Gill and Ratledge, 1972; Teh, 1974; Kato and Shibasaki, 1980; Kubo et al., 1995, 2003). This observation 
suggests that a factor other than the physicochemical properties of $n$-alcohols is also involved in the cutoff. Long-chain alcohols will inhibit the growth of microorganisms if the solubility reaches the MIC; otherwise, they would be cutoff compounds. If the cutoff chain length were determined by a balance between the solubility and the MIC, the cutoff chain length would be extended by a reduction in the MIC without a change in the physicochemical conditions. $\mathrm{C}_{12}$ inhibited the growth of BY4741, a wild-type strain, in 96-well plates at 24 hours, but not at 48 hours (Table 2). This transient inhibition is consistent with the observation in Fig. 4B. However, at 48 hours, $\mathrm{C}_{12}$ continued to inhibit the growth of W303, another wild-type strain, indicating that W303 is more sensitive to $\mathrm{C}_{12}$ than BY4741 (Table 2). Because W303 is defective in the SSD1 gene for cell wall formation (Ibeas et al., 2001), the cell wall is involved in the sensitivity to long-chain alcohols.

The yeast Pdr5 is a multidrug efflux pump [ATP-binding cassette $(\mathrm{ABC})$ transporter] that extrudes various lipophilic drugs; therefore, the pdr5 mutant is sensitive to drugs, decreasing the MICs (Balzi et al., 1994; Bissinger and Kuchler, 1994; Hirata et al., 1994). If Pdr5 extrudes the lipophilic long-chain alcohols, the mutant may be sensitive to alcohols. The MIC of $\mathrm{C}_{12}$ was variable at 48 hours but tended to be lower in the pdr5 mutant than in the wild-type parent (W303), although the MICs of both strains were the same at 24 hours (Table 2). This result is consistent with a previous report that the fungicidal activity of $\mathrm{C}_{12}$ is higher in the pdr5 mutant than in the wild-type strain (Fujita et al., 2017). Various MICs of $\mathrm{C}_{12}$ at 48 hours in budding yeast were also reported previously (Kubo et al., 2003). Presumably, various MICs of long-chain alcohols observed in these mutants are attributable to the nonuniform distributions caused by their high hydrophobicity, as described in Fig. 4B. These observations indicate that the pdr5 mutant is sensitive to long-chain alcohols. $\mathrm{C}_{13}$ transiently inhibited the growth of the pdr5 mutant at $25^{\circ} \mathrm{C}$ but not that of $\mathrm{W} 303$, indicating that the pdr5 mutant escapes the cutoff of $\mathrm{C}_{13}$ during a short-term incubation. The PDR 1 and $P D R 3$ genes are transcription factors for several $\mathrm{ABC}$ transporters in yeast. The $p d r 1,3,5$ triple mutant is more sensitive to various drugs than the pdr5 mutant is (Delaveau et al., 1994), as demonstrated by the sensitivity to $\mathrm{C}_{13} \cdot \mathrm{C}_{14}$ transiently inhibited the growth of the $p d r 1,3,5$ triple mutant but not that of the pdr5 mutant at $25^{\circ} \mathrm{C}$, although the MIC was variable at 24 hours (Table 2). Therefore, the $p d r 1,3,5$ mutant escapes the cutoff of $\mathrm{C}_{14}$ during a short-term incubation. Consequently, reducing the MIC of long-chain alcohols lengthens the cutoff chain length. By contrast, the overexpression of PDR5 confers resistance to various drugs and increases the MICs (Balzi et al., 1994; Bissinger and Kuchler, 1994; Hirata et al., 1994). The wildtype strain harboring $P D R 5$ on a multicopy vector was resistant to $1000 \mu \mathrm{M}$ of $\mathrm{C}_{12}$ at 48 hours, indicating that the overexpression of PDR5 shortens the cutoff chain length (Table 2). Collectively, the biological sensitivity to long-chain alcohols contributes to the cutoff.

\section{Discussion}

Increasing the physicochemical solubility of alcohols lengthens the cutoff chain length (Fig. 5A), and decreasing the MIC of alcohols lengthens the cutoff chain length (Fig. 5B). Therefore, a balance between the physicochemical properties and biological sensitivity determines the cutoff chain length. In general, when the aqueous solubility of a compound does not reach the critical concentration for the biological effect, the compound is a cutoff compound. This is similar to the hypothesis proposed by Ferguson (1939), which was supported by previous reports (Raines and Miller, 1994; Eckenhoff et al., 1999; Peoples and Ren, 2002). However, because the cutoff had not been elucidated, several hypotheses were proposed to explain the cutoff and focused on proteins and membranes. The reason for these confusions may have been the ambiguous definition of aqueous solubility. Therefore, we propose categorizing the aqueous solubility of $n$-alcohols into stable hydrated concentrations (HydC) and unstable mixed concentrations (MixC). Identifying these would be useful in explaining the various cutoff phenomena.

Cutoff lengths $\geq \mathrm{C}_{15}$ for various bacteria growing at approximately $37^{\circ} \mathrm{C}$ tend to be longer than those $\left(\geq \mathrm{C}_{12}\right)$ for various fungi at $25-30^{\circ} \mathrm{C}$ (Teh, 1974; Kato and Shibasaki, 1980; Kubo et al., 1995, 2003). Because destabilizing the solid-state structures of $\mathrm{C}_{13}\left(\mathrm{mp}: 32.5^{\circ} \mathrm{C}\right)$ and $\mathrm{C}_{14}\left(\mathrm{mp}: 37.7^{\circ} \mathrm{C}\right)$ at approximately $37^{\circ} \mathrm{C}$ increases their dissolution and releases free molecules, the total solubility $(\mathrm{HydC}+\mathrm{MixC})$ increases and reaches the MICs, thereby lengthening the cutoff chain

TABLE 2

MICs of long-chain alcohols determined in the $p d r$ mutants

A MICs (micromolar) were determined at $25^{\circ} \mathrm{C}$ in 96 -well plates containing $100 \mu \mathrm{l}$ of YPD and the indicated alcohols.

\begin{tabular}{|c|c|c|c|c|c|c|c|c|c|c|}
\hline \multirow{2}{*}{ Time (h) } & \multirow{2}{*}{$\frac{\mathrm{BY} 4741}{\mathrm{C}_{12}}$} & \multicolumn{3}{|c|}{ W303-1A } & \multicolumn{3}{|c|}{ pdr5s } & \multicolumn{3}{|c|}{$p d r 1 \Delta, 3 \Delta, 5 \Delta$} \\
\hline & & $\mathrm{C}_{12}$ & $\mathrm{C}_{13}$ & $\mathrm{C}_{14}$ & $\mathrm{C}_{12}$ & $\mathrm{C}_{13}$ & $\mathrm{C}_{14}$ & $\mathrm{C}_{12}$ & $\mathrm{C}_{13}$ & $\mathrm{C}_{14}$ \\
\hline 24 & 31 & 31 & n.d. & n.d. & 31 & 125 & n.d. & 31 & 63 & $63-125^{*}$ \\
\hline 48 & n.d. & 63 & n.d. & n.d. & $31-63^{*}$ & n.d. & n.d. & $31-63^{*}$ & 125 & n.d. \\
\hline
\end{tabular}

B W303-1A harboring YEp24 (vector) and YEp24-PDR5 $\left(P D R 5^{o x}\right.$ ) precultured in SD-U were grown at $25^{\circ} \mathrm{C}$ for 48 hours in 96 -well plates containing $100 \mu \mathrm{l}$ of YPD and the indicated alcohols. The identical MICs of the independent experiments are shown $(n \geq 3)$.

\begin{tabular}{|c|c|c|c|c|c|c|}
\hline \multirow{2}{*}{ Time (h) } & \multicolumn{3}{|c|}{ W303-1A/vector } & \multicolumn{3}{|c|}{$\mathrm{W} 303-1 \mathrm{~A} / P D R 5^{o x}$} \\
\hline & $\mathrm{C}_{10}$ & $\mathrm{C}_{12}$ & $\mathrm{C}_{13}$ & $\mathrm{C}_{10}$ & $\mathrm{C}_{12}$ & $\mathrm{C}_{13}$ \\
\hline 48 & 250 & $31-63^{*}$ & n.d. & 250 & n.d. & n.d. \\
\hline
\end{tabular}

n.d., MIC was not determined because the growth was observed at $1000 \mu \mathrm{M}$ for the indicated alcohols (cutoff).

*A range indicates that various MICs were observed. 


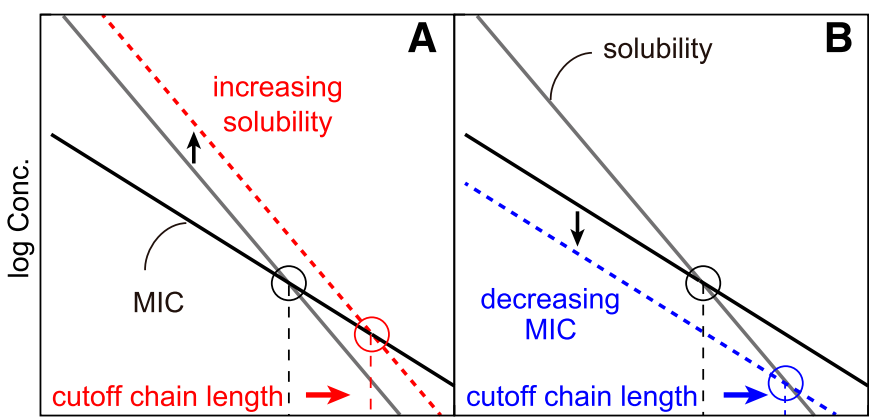

Alcohol chain length

Fig. 5. Physicochemical solubility of and biological sensitivity to longchain alcohols determine the cutoff chain length. Long-chain alcohols inhibit the growth of microorganisms when their solubilities reaches the MIC; however, when they do not, the alcohols are cutoff compounds. Increasing the solubility of alcohols lengthens the cutoff chain (A). Decreasing the MIC to alcohols lengthens the cutoff chain (B).

length in bacteria, as shown in Fig. 3. Therefore, the melting point of long-chain alcohols is responsible for the difference in the cutoff chain length between bacteria and fungi.

$n$-Alkanes also have antimicrobial activities and inhibitory activity against luciferase, although their cutoff chain length $\left(\geq \mathrm{C}_{7}\right)$ are shorter than those associated with $n$-alcohols (Gill and Ratledge, 1972; Teh and Lee, 1973; Franks and Lieb, 1985). Because the melting points of $n$-alkanes (e.g., $\leq \mathrm{C}_{16}$ : $\leq 18^{\circ} \mathrm{C}$ ) are lower than those of $n$-alcohols (e.g., $\leq \mathrm{C}_{16}: \leq 49^{\circ} \mathrm{C}$ ), they are not important for the cutoff of liquid alkanes. The hydrophobicity $(\log \mathrm{P})$ of $n$-alkanes is higher than that of $n$ alcohols with the same alkyl chain (TOXNET), because $n$ alkanes lack a hydroxyl group for hydration. Therefore, the HydC ( $S^{\text {liquid }}$ ) of liquid alkanes is lower than that for $n$-alcohols (eq. 1). Additionally, the densities are lower than those of $n$ alcohols (TOXNET). Because of their high hydrophobicity and low density, $n$-alkanes aggregate and separate from water more easily than do $n$-alcohols, resulting in a lower MixC. Hence, the total aqueous solubility $(\mathrm{HydC}+\mathrm{MixC})$ of $n$ alkanes is lower than that of $n$-alcohols (TOXNET). According to Fig. 5A, the low aqueous solubility of $n$-alkanes results in shorter-chain cutoffs compared with those of $n$-alcohols. By contrast, TMAs exhibit antimicrobial activity, even for $\mathrm{C}_{18}$ (Uesono et al., 2011). The hydrophobicity (logPs) is far lower than that of $n$-alcohols, resulting in high aqueous solubility (TOXNET), possibly because the ionic hydration of the quaternary ammonium group with water is stronger than the hydration of the alcoholic hydroxyl group. Thus, TMAs easily reach the MIC. Because the melting points of TMAs are higher than $150^{\circ} \mathrm{C}$ (TOXNET), hydrophobicity is more important than the melting point for the cutoff, as described for $n$ alkanes.

No growth inhibition was observed for the shaking cultures of the thermophilic bacterium treated with $\mathrm{C}_{18}\left(\mathrm{mp}: 59.5^{\circ} \mathrm{C}\right)$ at $67.5^{\circ} \mathrm{C}$ (Fig. 3B) or of the yeast treated with $\mathrm{C}_{18: 1}\left(\mathrm{mp}: 7^{\circ} \mathrm{C}\right)$ at $25^{\circ} \mathrm{C}$ (data not shown), above their melting points. Because these alcohols have densities similar to those of short-chain alcohols $\left(\geq \mathrm{C}_{4}\right.$ ) (Supplemental Table 1), their high hydrophobicity owing to the long chains should be important for the cutoff, rather than the melting points and the densities. Longchain solid alcohols delay the growth of Staphylococcus aureus in a shaking culture at $37^{\circ} \mathrm{C}$, below their melting points, and the time required for the delay decreases with their chain length $\left(\mathrm{C}_{14}: 29.7\right.$ hours, $\mathrm{C}_{16}$ : 17.3 hours, $\mathrm{C}_{18}: 10$ hours $)$ (Togashi et al., 2007). Therefore, solid alcohols have antimicrobial activity within short-term incubations, although they are judged as cutoff compounds in long-term incubation (Fig. $4 \mathrm{~B}$; Table 2). Because these alcohols $\left(\mathrm{C}_{14}-\mathrm{C}_{18}\right)$ have similar densities (Supplemental Table 1), the difference in the delays is attributable to the hydrophobicity, rather than the melting points and densities. The long-chain solid alcohols also probably exist in the aqueous phase as hydrated and mixed concentrations (Fig. 2). Therefore, the duration of the delay decreases with decreases in the MixCs (the increase in the aggregation rate) determined by the chain length. Collectively, the high hydrophobicity, rather than the high melting point and low density of these alcohols, is important for the cutoff.

The cutoff chain length of alcohols for firefly luciferase inhibition $\left(\geq \mathrm{C}_{17}\right)$ is abnormally longer than the cutoff chain length $\left(\geq \mathrm{C}_{13}\right)$ observed in various biological systems (Ingólfsson and Andersen, 2011). Firefly luciferase is similar to rat long-chain acyl-CoA synthetase (Suzuki et al., 1990) and catalyzes the formation of fatty acyl-CoA from long-chain fatty acid as a substrate (Oba et al., 2003). Therefore, luciferase is considered to have as high an affinity for long-chain alcohols as do fatty acids. Consequently, alcohols may inhibit luciferase at lower concentrations, resulting in the high sensitivity of luciferase to long-chain alcohols. According to Fig. 5B, the high biological sensitivity lengthens the cutoff chain length for luciferase inhibition. In addition, $n$-alcohols $\left(\mathrm{C}_{18}\right)$ partially inhibit luciferase activity, more weakly than the inhibition by $\mathrm{C}_{16}$ (Ueda and Suzuki, 1998). This apparently differs from the typical cutoff phenomenon: complete loss of biological activity. The difference between $\mathrm{C}_{16}$ and $\mathrm{C}_{18}$ may reflect the effect on solubility resulting from the nonuniform distribution of $n$ alcohols in the solution, compared to the uniform distribution of luciferase.

The cutoff length of straight-chain diols $\left(\geq \mathrm{C}_{14}\right)$ for inhibition of the NMDA receptor is longer than that of $n$-alcohols $\left(\geq \mathrm{C}_{10}\right)$ (Peoples and Ren, 2002). This could be explained by Fig. 5A, because the solubilities of diols having two hydroxyl groups are higher than those of alcohols. However, the cutoff lengths for the inhibition of P2X receptor are abnormally short $\left(\geq \mathrm{C}_{4}\right)$ (Weight et al., 1999). This may be owing to another mechanism because it is not resistant to alcohols.

The minimum concentration required for anesthetics and alcohols to affect microorganisms with cell walls is higher than that required to affect animals without cell walls (Fig. 1; Table 2) (Pringle et al., 1981; Kubo et al., 1995, 2003; Keil et al., 1996). This observation suggests that the cell wall is involved in sensitivity to anesthetics and alcohols. The cutoff chain length $\left(\geq \mathrm{C}_{8}\right)$ for Gram negative bacteria are shorter than those $\left(\geq \mathrm{C}_{13}\right)$ for Gram positive bacteria (Kubo et al., 1995). The cell walls of these groups are quite different. Gram negative bacteria have double membrane structures and a thin wall, whereas Gram positive bacteria have a single membrane structure and a thick wall. Therefore, long-chain alcohols with low aqueous solubility do not reach the MIC of Gram negative bacteria protected by complex membrane structures, thereby shortening the cutoff length. This indicates that the membrane structure is a determinant of the cutoff phenomenon, rather than wall thickness. ABC transporters affected the cutoff chain length of $n$-alcohols in yeast (Table 2), indicating that the membrane state, such as the 
alcohol sensitivity, possibly defined by the efflux of lipophilic long-chain alcohols, is another determinant for the cutoff. Collectively, both the structure and state of the biological membrane defining the alcohol sensitivity contribute to the cutoff.

The maximum chain length $\left(\mathrm{C}_{13}\right)$ for the anesthesia of a tadpole is longer than $\mathrm{C}_{12}$ for yeast growth inhibition (Pringle et al., 1981). This is because the alcohol sensitivity of a tadpole is higher than that of yeast with a cell wall (Table 2). However, $\mathrm{C}_{13}$ also had no anesthetic effect in a later study (Alifimoff et al., 1989). This discrepancy may be caused by the equilibration treatment of $\mathrm{C}_{13}$ performed in the later study, because the long-term treatment reduced the $\mathrm{MixC}$ at the bottom of the container owing to low density and high hydrophobicity (Fig. 2B; Fig. 4, B and C; Table 2). The decreased total solubility with $\mathrm{HydC}$ did not reach the anesthetic concentration for a tadpole, resulting in the cutoff of $\mathrm{C}_{13}$. Accordingly, our theory derived from microbial experiments may also be applicable to the anesthetic cutoff of animals.

The cutoff phenomenon of long-chain alcohols can be escaped by increasing alcohol solubility. Thus, the cutoff can be explained by a mechanism other than the special pocket in proteins and the membrane alteration. Additionally, earlier explanations of the cutoff proposed complicated equations, such as the parabolic model and the bilinear model, to quantitate the structure-activity relationship (Hansch, 1969; Kubinyi, 1977). However, they may be simplified as reported previously (Meyer and Hemmi, 1935; Hansch and Dunn, 1972): There is no necessity to consider the cutoff compounds, because they do not reach biologically active concentrations. Increasing the aqueous solubility of hydrophobic compounds is the way to detect unknown biological effects. If the low solubility of high hydrophobic compounds such as long-chain alcohols is improved and the cutoff is escaped, the correlation between biological effects and the chain length (hydrophobicity) is correctly evaluated, as seen for water-soluble compounds (Williams et al., 2007; Uesono et al., 2011).

\section{Acknowledgments}

We thank Masaki Mizunuma, Dai Hirata, and Yoshiyuki Tsujimoto for providing plasmids and strains, Naoki Kajiyama and Tsutomu Morinaga for useful information on luciferase and thermophilic bacteria, and Ichiro Terashima for valuable suggestions.

\section{Authorship Contributions}

Participated in research design: Matsumoto, Uesono.

Conducted experiments: Matsumoto.

Performed data analysis: Matsumoto, Uesono.

Wrote or contributed to the writing of the manuscript: Matsumoto, Uesono.

\section{References}

Alifimoff JK, Firestone LL, and Miller KW (1989) Anaesthetic potencies of primary alkanols: implications for the molecular dimensions of the anaesthetic site. $\mathrm{Br} J$ Pharmacol 96:9-16.

Antkowiak B (2001) How do general anaesthetics work? Naturwissenschaften 88: 201-213.

Balzi E, Wang M, Leterme S, Van Dyck L, and Goffeau A (1994) PDR5, a novel yeast multidrug resistance conferring transporter controlled by the transcription regulator PDR1. J Biol Chem 269:2206-2214.

Bell GH (1973) Solubilities of normal aliphatic acids, alcohols and alkanes in water. Chem Phys Lipids 10:1-10.

Bissinger PH and Kuchler K (1994) Molecular cloning and expression of the Saccharomyces cerevisiae STS1 gene product. A yeast ABC transporter conferring mycotoxin resistance. J Biol Chem 269:4180-4186.

Cantor RS (2001) Breaking the Meyer-Overton rule: predicted effects of varying stiffness and interfacial activity on the intrinsic potency of anesthetics. Biophys $J$ 80:2284-2297.
Carignan D, Désy O, Ghani K, Caruso M, and de Campos-Lima PO (2013) The size of the unbranched aliphatic chain determines the immunomodulatory potency of short and long chain n-alkanols. J Biol Chem 288:24948-24955.

Chiou JS, Ma SM, Kamaya H, and Ueda I (1990) Anesthesia cutoff phenomenon: interfacial hydrogen bonding. Science 248:583-585

Delaveau T, Delahodde A, Carvajal E, Subik J, and Jacq C (1994) PDR3, a new yeast regulatory gene, is homologous to PDR1 and controls the multidrug resistance phenomenon. Mol Gen Genet 244:501-511.

Eckenhoff RG, Tanner JW, and Johansson JS (1999) Steric hindrance is not required for $n$-alkanol cutoff in soluble proteins. Mol Pharmacol 56:414-418.

Ferguson J (1939) The use of chemical potentials as indices of toxicity. Proc $R$ Soc Lond B Biol Sci 127:387-404.

Franks NP and Lieb WR (1985) Mapping of general anaesthetic target sites provides a molecular basis for cutoff effects. Nature 316:349-351.

Franks NP and Lieb WR (1990) Mechanisms of general anesthesia. Environ Health Perspect 87:199-205.

Fujita KI, Ishikura T, Jono Y, Yamaguchi Y, Ogita A, Kubo I, and Tanaka T (2017) Anethole potentiates dodecanol's fungicidal activity by reducing PDR5 expression in budding yeast. Biochim Biophys Acta, Gen Subj 1861:477-484.

Gill CO and Ratledge C (1972) Toxicity of $n$-alkanes, $n$-Alk-1-enes, $n$-alkan-1-ols and $n$-alkyl-1-bromides towards yeasts. Microbiology 72:165-172.

Guthrie C and Fink GR (1991) Guide to Yeast Genetics and Molecular Biology, Vol. 194. Academic Press/Elsevier, Cambridge, MA.

Hansch C (1969) Quantitative approach to biochemical structure-activity relationships. Acc Chem Res 2:232-239.

Hansch C and Dunn WJ III (1972) Linear relationships between lipophilic character and biological activity of drugs. J Pharm Sci 61:1-19.

Hirata D, Yano K, Miyahara K, and Miyakawa T (1994) Saccharomyces cerevisiae YDR1, which encodes a member of the ATP-binding cassette (ABC) superfamily, is required for multidrug resistance. Curr Genet 26:285-294.

Ibeas JI, Yun DJ, Damsz B, Narasimhan ML, Uesono Y, Ribas JC, Lee H, Hasegawa PM, Bressan RA, and Pardo JM (2001) Resistance to the plant PR-5 protein osmotin in the model fungus Saccharomyces cerevisiae is mediated by the regulatory effects of SSD1 on cell wall composition. Plant $J$ 25:271-280.

Ingólfsson HI and Andersen OS (2011) Alcohol's effects on lipid bilayer properties. Biophys $J$ 101:847-855.

Jain N and Yalkowsky SH (2001) Estimation of the aqueous solubility I: application to organic nonelectrolytes. J Pharm Sci 90:234-252.

Kamaya H, Matubayasi N, and Ueda I (1984) Biphasic effect of long-chain $n$-alkanols on the main phase transition of phospholipid vesicle membranes. J Phys Chem 88: $797-800$.

Kato N and Shibasaki I (1980) The antimicrobial characteristics of 1 -alkanols. $J$ Antibact Antifung Agents 8:325-331.

Keil RL, Wolfe D, Reiner T, Peterson CJ, and Riley JL (1996) Molecular genetic analysis of volatile-anesthetic action. Mol Cell Biol 16:3446-3453.

Kubinyi H (1977) Quantitative structure-activity relationships. 7. The bilinear model, a new model for nonlinear dependence of biological activity on hydrophobic character. J Med Chem 20:625-629.

Kubo I, Fujita T, Kubo A, and Fujita Ki (2003) Modes of antifungal action of alkanols against Saccharomyces cerevisiae. Bioorg Med Chem 11:1117-1122.

Kubo I, Muroi H, and Kubo A (1995) Structural functions of antimicrobial long-chain alcohols and phenols. Bioorg Med Chem 3:873-880.

Krause FP and Lange W (1965) Aqueous solubilities of $n$-dodecanol, $n$-hexadecanol, and $n$-octadecanol by a new method. J Phys Chem 69:3171-3173.

Meyer H (1899) Zur theorie der Alkoholnarkose. Arch Exp Pathol Pharmakol 42: $109-118$.

Meyer HH and Hemmi H (1935) Beitrage zur Theorie der Narkose, III. Biochem Z 277:39-71.

Mohr JT, Gribble GW, Lin SS, Eckenhoff RG, and Cantor RS (2005) Anesthetic potency of two novel synthetic polyhydric alkanols longer than the n-alkanol cutoff: evidence for a bilayer-mediated mechanism of anesthesia? J Med Chem 48: 4172-4176

Msadek T, Dartois V, Kunst F, Herbaud ML, Denizot F, and Rapoport G (1998) ClpP of Bacillus subtilis is required for competence development, motility, degradative enzyme synthesis, growth at high temperature and sporulation. Mol Microbiol 27 899-914.

Mukherjee K, Tribedi P, Mukhopadhyay B, and Sil AK (2013) Antibacterial activity of long-chain fatty alcohols against mycobacteria. FEMS Microbiol Lett 338:177-183.

Oba Y, Ojika M, and Inouye S (2003) Firefly luciferase is a bifunctional enzyme: ATPdependent monooxygenase and a long chain fatty acyl-CoA synthetase. FEBS Lett 540:251-254.

Overton E (1901) Studien über die Narkose, zugleich ein Beitrag zur allgemeiner Pharmakologie, Verlag von Gustav Fischer, Jena, Germany.

Peoples RW and Ren H (2002) Inhibition of $N$-methyl-D-aspartate receptors by straight-chain diols: implications for the mechanism of the alcohol cutoff effect. $M o l$ Pharmacol 61:169-176.

Pringle MJ, Brown KB, and Miller KW (1981) Can the lipid theories of anesthesia account for the cutoff in anesthetic potency in homologous series of alcohols? $\mathrm{Mol}$ Pharmacol 19:49-55.

Raines DE and Miller KW (1994) On the importance of volatile agents devoid of anesthetic action. Anesth Analg 79:1031-1033.

Suzuki H, Kawarabayasi Y, Kondo J, Abe T, Nishikawa K, Kimura S, Hashimoto T, and Yamamoto T (1990) Structure and regulation of rat long-chain acyl-CoA synthetase. J Biol Chem 265:8681-8685.

Teh JS (1974) Toxicity of short-chain fatty acids and alcohols towards Cladosporium resinae. Appl Microbiol 28:840-844.

Teh JS and Lee KH (1973) Utilization of $n$-alkanes by Cladosporium resinae. Appl Microbiol 25:454-457.

Togashi N, Shiraishi A, Nishizaka M, Matsuoka K, Endo K, Hamashima H, and Inoue Y (2007) Antibacterial activity of long-chain fatty alcohols against Staphylococcus aureus. Molecules 12:139-148. 
Tsujimoto Y, Shimizu Y, Otake K, Nakamura T, Okada R, Miyazaki T, and Watanabe K (2015) Multidrug resistance transporters Snq2p and Pdr5p mediate caffeine efflux in Saccharomyces cerevisiae. Biosci Biotechnol Biochem 79:1103-1110.

Tutulan-Cunita AC, Mikoshi M, Mizunuma M, Hirata D, and Miyakawa T (2005) Mutational analysis of the yeast multidrug resistance ABC transporter Pdr5p with altered drug specificity. Genes Cells 10:409-420.

Ueda I (1965) Effects of diethyl ether and halothane on firefly luciferin bioluminescence. Anesthesiology 26:603-606.

Ueda I and Suzuki A (1998) Is there a specific receptor for anesthetics? Contrary effects of alcohols and fatty acids on phase transition and bioluminescence of firefly luciferase. Biophys J 75:1052-1057.

Uesono Y, Toh-E A, Kikuchi Y, and Terashima I (2011) Structural analysis of compounds with actions similar to local anesthetics and antipsychotic phenothiazines in yeast. Yeast 28:391-404.
Urban BW, Bleckwenn M, and Barann M (2006) Interactions of anesthetics with their targets: non-specific, specific or both? Pharmacol Ther 111:729-770.

Weight FF, Li C, and Peoples RW (1999) Alcohol action on membrane ion channels gated by extracellular ATP (P2X receptors). Neurochem Int 35:143-152.

Williams AA, Sugandhi EW, Macri RV, Falkinham JO III, and Gandour RD (2007) Antimicrobial activity of long-chain, water-soluble, dendritic tricarboxylato amphiphiles. J Antimicrob Chemother 59:451-458.

Address correspondence to: Dr. Yukifumi Uesono, Department of Biological Sciences, Graduate School of Science, The University of Tokyo, 7-3-1 Hongo, Bunkyo-ku, Tokyo 113-0033, Japan. E-mail: uesono@bs.s.u-tokyo.ac.jp 